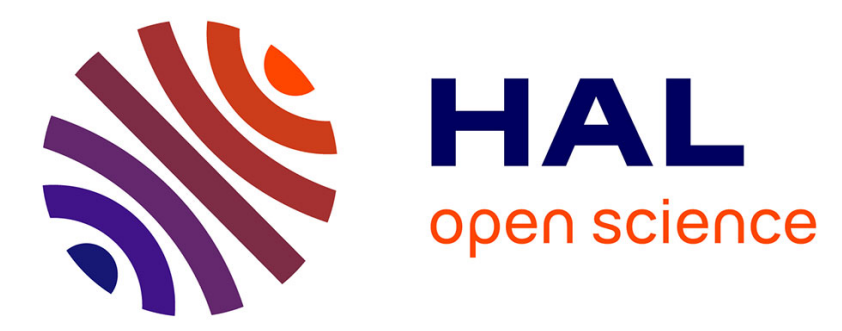

\title{
Chiral Phosphate in Rhodium-Catalyzed Asymmetric [2+2+2] Cycloaddition: Ligand, Counterion, or Both?
}

\author{
Marion Barbazanges, Elsa Caytan, Denis Lesage, Corinne Aubert, Louis
}

Fensterbank, Vincent Gandon, Cyril Ollivier

\section{- To cite this version:}

Marion Barbazanges, Elsa Caytan, Denis Lesage, Corinne Aubert, Louis Fensterbank, et al.. Chiral Phosphate in Rhodium-Catalyzed Asymmetric $[2+2+2]$ Cycloaddition: Ligand, Counterion, or Both?. Chemistry - A European Journal, 2016, 22 (25), pp.8553-8558. 10.1002/chem.201601188 . hal01314957

\section{HAL Id: hal-01314957 \\ https://hal.sorbonne-universite.fr/hal-01314957}

Submitted on 12 May 2016

HAL is a multi-disciplinary open access archive for the deposit and dissemination of scientific research documents, whether they are published or not. The documents may come from teaching and research institutions in France or abroad, or from public or private research centers.
L'archive ouverte pluridisciplinaire HAL, est destinée au dépôt et à la diffusion de documents scientifiques de niveau recherche, publiés ou non, émanant des établissements d'enseignement et de recherche français ou étrangers, des laboratoires publics ou privés. 


\title{
Chiral Phosphate in Rhodium-Catalyzed Asymmetric [2+2+2] Cycloaddition: Ligand, Counterion or Both?
}

\author{
Marion Barbazanges, ${ }^{*[a]}$ Elsa Caytan, ${ }^{[b]}$ Denis Lesage,${ }^{[a]}$ Corinne Aubert, ${ }^{*[a]}$ Louis Fensterbank, ${ }^{*[a]}$ \\ Vincent Gandon, ${ }^{[\mathrm{c}][\mathrm{dd}]}$ Cyril Ollivier ${ }^{[\mathrm{a}]}$
}

\begin{abstract}
Investigations based on NMR, MS and DFT studies shed light on the metallic species generated in the rhodiumcatalyzed asymmetric $[2+2+2]$ cycloaddition reaction between diynes and isocyanates with a chiral TRIP phosphate. The $[\mathrm{Rh}(\mathrm{COD}) \mathrm{Cl}]_{2} / \mathrm{dppb} / \mathrm{Ag}(S)$-TRIP catalytic mixture actually gives rise to two species, both having an effect on the stereoselectivity. One is a rhodium(I) complex in which the TRIP is a weakly coordinating counterion. The other one is a bimetallic $\mathrm{Rh} / \mathrm{Ag}$ complex where the TRIP is a strongly coordinating X-type ligand.
\end{abstract}

\section{Introduction}

Enantioselective metal-catalyzed transformations are a cornerstone of modern synthetic organic chemistry. ${ }^{[1],[2]}$ Over the last decade, the limits of this discipline have been pushed even further, notably through the design of original ligands ${ }^{[3]}$ or the use of multiple stereodifferentiation approaches. ${ }^{[4]}$ Recent years have also witnessed the rise of the Asymmetric Counterion Directed Catalysis (ACDC) approach. In this case, the counterion of a catalytically active cationic metal species is employed as vehicle of the stereochemical information to be transferred to the reaction products. ${ }^{[5]}$ Disclosed in 2000 by Arndtsen in a copper-catalyzed borate-assisted styrene aziridination, ${ }^{[6]}$ ACDC has known an intense interest following the reports of Krische, List and Toste in 2006 and 2007..$^{[7],[8]}$ The use of the BINOL-derived hindered phosphate [TRIP] $]^{-}$as the chirality carrier ${ }^{[9]}$ constituted a real breakthrough as high ees

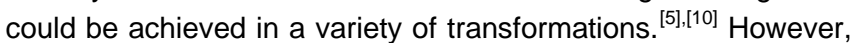
the exact nature of the phosphate chirality carrier, i.e. X-type ligand or counterion, is often a source of controversy. If it remains somehow bound to the metal during the stereochemistry determining step, then its mode of action is not

[a] Dr. M. Barbazanges, Dr. D. Lesage, Dr. C. Aubert, Pr. L. Fensterbank, Dr. C. Ollivier, Sorbonne Universités, UPMC UNIV. Paris 06, Institut Parisien de Chimie Moléculaire (UMR CNRS 8232), Case Courrier 229, 4 place Jussieu, 75252 Paris Cedex 05, France

E-mails: marion.barbazanges@upmc.fr; corinne.aubert@upmc.fr; louis.fensterbank@upmc.fr

[b] Dr. E. Caytan, Institut des Sciences Chimiques de Rennes, Université de Rennes 1, Campus de Beaulieu, 35042 Rennes Cedex, France

[c] Pr. V. Gandon, ICMMO, Univ. Paris-Sud, CNRS UMR 8182 , Université Paris-Saclay, 91405 Orsay cedex, France

[d] ICSN, CNRS UPR 2301, Univ. Paris-Sud, Université ParisSaclay, 91198 Gif-sur-Yvette, France

Supporting information for this article is given via a link at the end of the document. very different from a classical L-type monodentate ligand. If it is well separated from the metal center (loose ion pair), then the transfer of the stereochemical information would require an anchoring of the counterion on the ligands or on the substrate itself. ${ }^{[11]}$ In this case, the induction models should be completely distinct. To date, no report has brought firm evidence on this issue. The strong dependence of the ee on solvent polarity suggests that a large interionic distance is deleterious to the chirality transfer but does not inform on the actual location of the phosphate. ${ }^{[12]} \mathrm{X}$-ray structure analyses generally reveal short metal-oxygen bond lengths, thus in agreement with a strong covalent bonding. ${ }^{[13]}$ However, this does not mean that such bonds remain covalent or endure solvation during catalysis. For instance, while the phosphate gold complexes $\mathbf{A}$ and $\mathbf{B}$ were proved to be covalent in $\mathrm{CD}_{2} \mathrm{Cl}_{2}$ (Figure 1), ${ }^{[13 b],[14]}$ the phosphate moiety is believed to be a "true" counterion in catalysis due to the linear geometry of the $\left[\left(\mathrm{R}_{3} \mathrm{P}\right) \mathrm{Au}(\text { substrate })\right]^{+}$complex $\mathbf{C}$ which imposes the phosphate keeping off the coordination sphere of the metal to allow substrate activation. ${ }^{[8]}$ This reasoning based on geometrical constraints cannot be so obviously applied with metal ions of $\mathrm{Ir}, \mathrm{Pd}, \mathrm{Cu}, \mathrm{Ru}$ or $\mathrm{Rh} .{ }^{[15]}$ In that case, DFT studies have been helpful to support a counterion role of the phosphate on the $\operatorname{Ir}$ complex $\mathbf{D},{ }^{[10 c]}$ and on the palladium complex E. ${ }^{[16]}$ However, no physical evidence on the counterion or ligand nature of the phosphate has been reported so far.

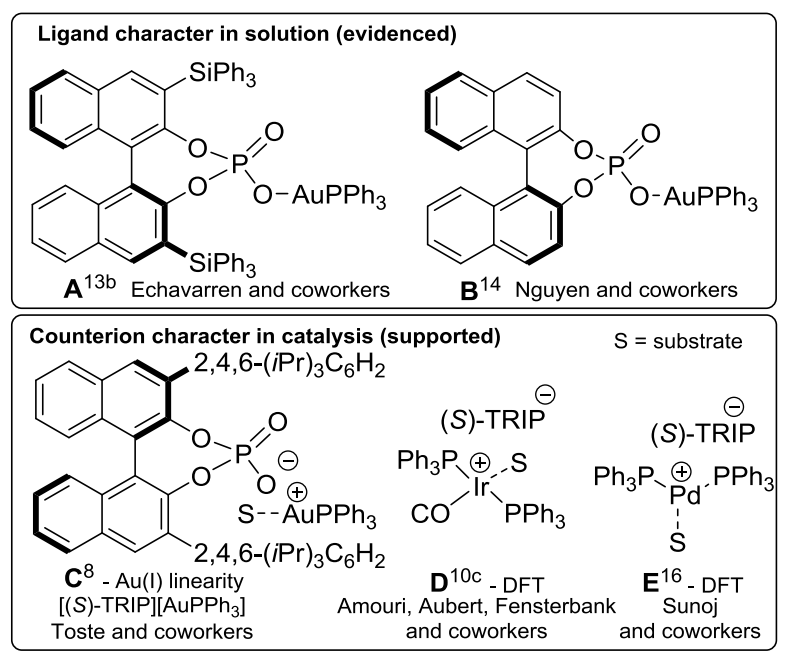

Figure 1. Ligand vs counterion character of chiral phosphates in transition metal complexes. 
We describe herein a study aimed at shedding light on the issue of the ligand or counterion nature of a chiral phosphate on catalytically active square planar $\mathrm{Rh}^{+}$complexes. We have recently reported the first case of chiral phosphate-directed asymmetric $[2+2+2]$ cycloaddition (Scheme 1). ${ }^{[10 b]}$ We have shown that diynes 1 and isocyanates 2 lead to enantiomerically enriched pyridones 3 in up to $91 / 9$ er, in the presence of the [( $S$ TRIP] $]^{-}$phosphate (Figure 2) as the sole chirality source of a catalytic mixture comprising $[\mathrm{Rh}(\mathrm{COD}) \mathrm{Cl}]_{2}$, 1,4diphenylphosphinobutane (dppb), and $\mathrm{Ag}(S)$-TRIP. A likely component of this mixture would be $\operatorname{Rh}(C O D)(d p p b)((S)-T R I P)$ formed after chloride abstraction by the silver salt. Such a complex could adopt various coordination modes. Even though the square planar geometry should be always favored, the phosphate could be an X-type ligand if COD or dppb acts as a monodentate ligand. On the other hand, if both COD and dppb allow an $\eta^{2}, \eta^{2}$-Rh complex, then the phosphate should be a counterion as in [l] $]^{+}((S)-T R I P]^{-}$(Figure 2) and the complex could be either a tight or a loose ion pair. Under the optimized conditions, $\mathrm{Ag}(S)$-TRIP is used in a 1.5 -fold excess compared to $\mathrm{Rh}$. If the anion metathesis is complete, $2.5 \mathrm{~mol} \%$ of $\mathrm{Ag}(S)$-TRIP should still be present. Since the silver complex is not catalytically active, the impact of the presence of this salt on the stereoselectivity is puzzling. Thus, we decided to study carefully the species contained in this catalytic mixture ${ }^{[17]}$ focusing on the nature, ligand or counterion, of the chiral phosphate.

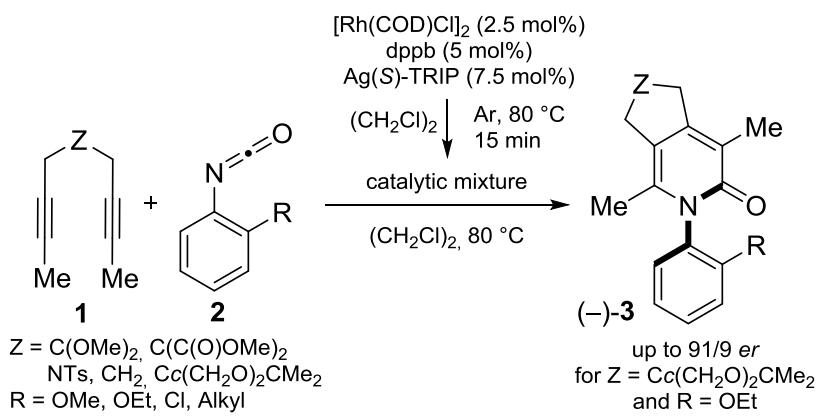

Scheme 1. Rh-ACDC catalyzed $[2+2+2]$ cycloaddition. ${ }^{[10 b]}$

\section{Results and Discussion}

We first examined the species formed when mixing $\left[\mathrm{Rh}(\mathrm{COD}) \mathrm{Cl}_{2}\right.$ (0.5 equiv), dppb (1 equiv) and $\mathrm{Ag}(\mathrm{S})$-TRIP (1 equiv) in $\left(\mathrm{CH}_{2} \mathrm{Cl}\right)_{2}$ at $80^{\circ} \mathrm{C}$ under argon for $15 \mathrm{~min}$ (sealed NMR tube), which corresponds to the premix conditions for the cycloaddition reaction shown in Scheme 1. 1D and 2D NMR experiments were in agreement with the proposed structure []$^{+}[(S)-T R I P]^{-}$shown on Figure 2 (see SI, sections 2.1 to 2.3 ). The formation of this species at room temperature in $\mathrm{CD}_{2} \mathrm{Cl}_{2}$ was also ascertained by NMR. ${ }^{[18]}$ In particular, the ${ }^{31} \mathrm{P}$ spectrum shows two signals, one accounting for the dppb ligand $(\delta 24.6$ ppm, $\left.d, J\left({ }^{103} \mathrm{Rh}-{ }^{31} \mathrm{P}\right)=144 \mathrm{~Hz}\right)$ and the other for the phosphate (broad s, $\delta 4.8 \mathrm{ppm}) .{ }^{[18]}$ The ${ }^{1} \mathrm{H}-{ }^{103} \mathrm{Rh} \mathrm{HMQC}$ spectrum shows a triplet at $\delta$-8466 ppm. ${ }^{[19],[20 a]}$ This is consistent with a $\mathrm{Rh}(\mathrm{P})_{2}$ (alkene $)_{n}$ type complex. ${ }^{[21]}$ ESI experiments carried out on the mixture also confirmed this hypothesis, as both cation [I] ${ }^{+}$ (positive mode, $\mathrm{m} / \mathrm{z}$ 637, Figure 3 ) and anion $[(S)$-TRIP] (negative mode, $\mathrm{m} / \mathrm{z} 751$ ) were detected (SI, section 2.4).<smiles>O=P([O-])(O)Oc1c(Br)cc2ccccc2c1-c1c(Br)cc2ccccc2c1Br</smiles>

$\left[(S)-\right.$ TRIP] $^{-}$ $\left(\mathrm{Ar}=2,4,6-(\mathrm{iPr})_{3} \mathrm{C}_{6} \mathrm{H}_{2}\right)$

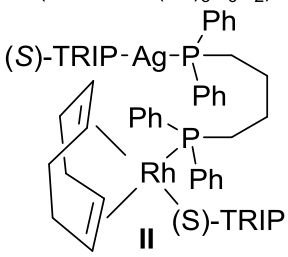<smiles>C1=C(P(c2ccccc2)P(c2ccccc2)(c2ccccc2)(c2ccccc2)c2ccccc2)CC2CCC1CC2</smiles>

(S)-TRIP ${ }^{\Theta}$

[]$^{+}[(S)-T R I P]$

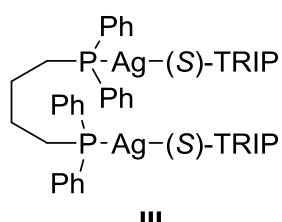

III
Figure 2. Species involved in this study.

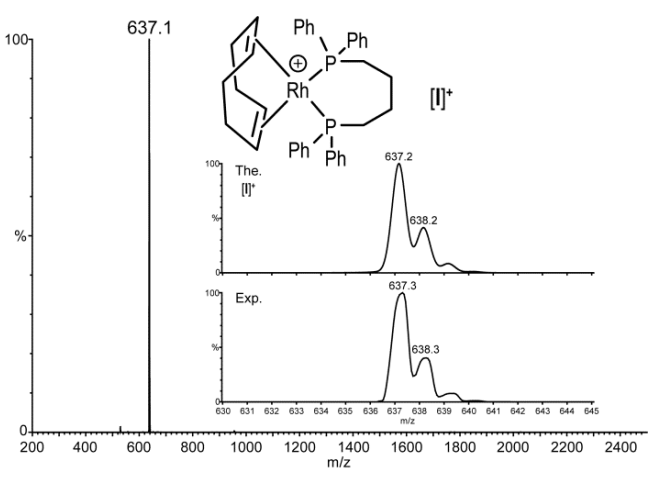

Figure 3. Simulation and experimental ESI (positive mode) of species $\left[\mathrm{I}^{+}[(S)\right.$ TRIP].

The question of the interaction between [I] $]^{+}$and [(S)-TRIP] remained to be answered. In addition to conductivity measurements, IR, and 1D NMR investigations, ${ }^{[6],[13 \mathrm{~b}]}$ a powerful tool to evidence ion pairing is the Diffusion Ordered SpectroscopY experiment (DOSY). This technique has been extensively used by Pregosin and Macchioni to study cationic organometallic species. ${ }^{[22]}$ To date, application of this method to complexes relevant to ACDC is limited to a single example:[23] for $[\mathrm{Rh}(\mathrm{COD})(\mathrm{BINAP})]\left[\mathrm{B}(\mathrm{BINOL})_{2}\right]$, Brown and coworkers observed the same diffusion coefficient for $[R h(C O D)(B I N A P)]$ and $\left[\mathrm{B}(\mathrm{BINOL})_{2}\right]$. It was therefore concluding that this complex is the intimate $[\mathrm{Rh}(\mathrm{COD})(\mathrm{BINAP})]^{+}\left[\mathrm{B}(\mathrm{BINOL})_{2}\right]^{-}$ion pair in solution, the assembly of the two ionic entities being achieved through 
non-covalent interactions. To definitively settle the ligand or counterion character of $(S)$-TRIP in [I][(S)-TRIP], we carried out three NMR experiments: i) a $1 \mathrm{D} \mathrm{HMQC}{ }^{31} \mathrm{P}-{ }^{103} \mathrm{Rh}$ to detect long range couplings between the phosphate and the rhodium nucleus, ii) 2D NOESY and ROESY to detect any non-covalent interaction between the phosphate and the ligands, and iii) a DOSY (Figure 4). The first two experiments showed no phosphate- ${ }^{103} \mathrm{Rh}$ correlation signal (SI, section 2.2) or phosphate/ligand interaction (SI, section 2.6). The DOSY led to the following diffusions coefficients: $D_{[\mathrm{TRIP}]}=7.5 \mathrm{E}-10 \mathrm{~m}^{2} / \mathrm{s}$ (i.e. a hydrodynamic radii of $r_{H}=7.2 \AA$ ); $D_{[l]}=8.7 \mathrm{E}-10 \mathrm{~m}^{2} / \mathrm{s}$ (i.e. $\left.r_{H}=6.2 \AA\right)$ (SI, section 2.6). ${ }^{[24],[25],[26]}$ Since the two fragments have different diffusion coefficients, it is clear that they move independently. On the basis of these three experiments, it can be concluded that $\left[(S)-\mathrm{TRIP}^{-}\right.$can be qualified as counterion and that complex []$^{+}[(S)-T R I P]^{-}$behaves as a loose ion pair in solution.

[]$^{+}[(S)-T R I P]^{-}$was independently synthesized in order to evaluate its catalytic activity and stereoselectivity. This isolated complex, which NMR data fits with those of the in situ generated species discussed above, was tested in a $[2+2+2]$ cycloaddition between diyne $\mathbf{1 a}$ and isocyanate $\mathbf{2 a}$ and led to the desired pyridone (-)-3a in $79 \%$ yield (Scheme 2, conditions B). Surprisingly, a decrease of the enantiomeric ratio from $85 / 15$ in the ACDC-optimized conditions (conditions A) to $75 / 25$ was observed. The results of conditions $A$ and $B$ were reproducible (SI, section 2.5).
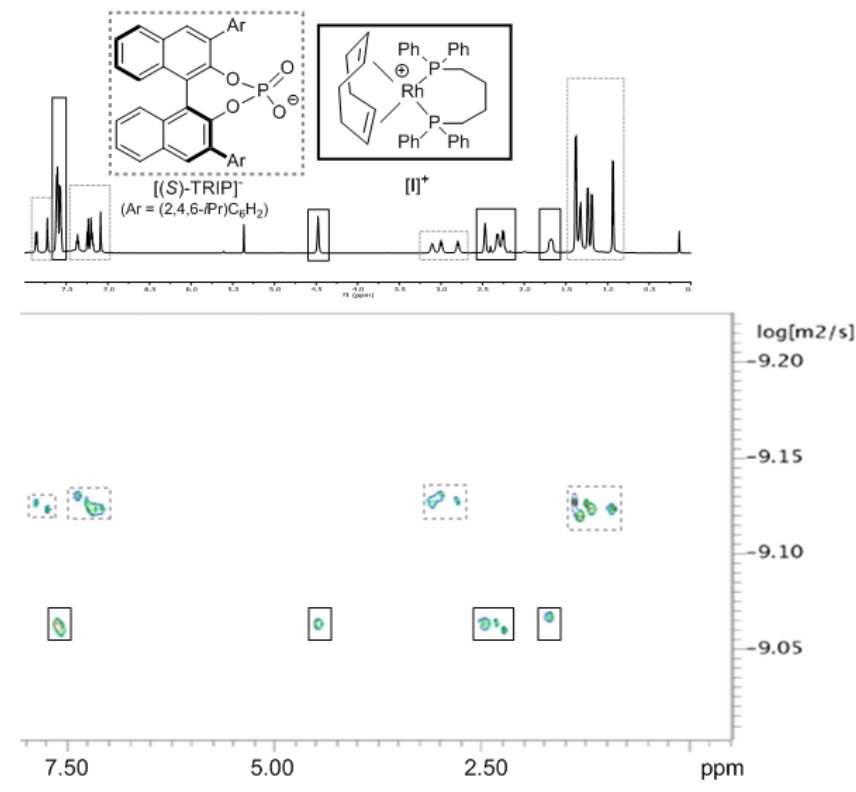

Figure 4. DOSY experiment $\left(\mathrm{CD}_{2} \mathrm{Cl}_{2}, 600 \mathrm{MHz}, 300 \mathrm{~K}\right)$.

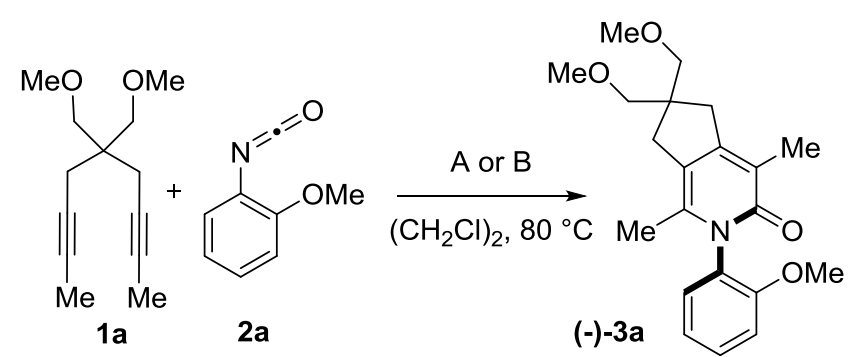

Cond. A: i) $\left[\mathrm{Rh}(\mathrm{COD}) \mathrm{Cl}_{2}(2.5 \mathrm{~mol} \%)\right.$, dppb (5 mol\%), $\mathrm{Ag}(\mathrm{S})$-TRIP $(7.5 \mathrm{~mol} \%)$,

$77 \%, 85 / 15$ er $\left(\mathrm{CH}_{2} \mathrm{Cl}\right)_{2}, 80^{\circ} \mathrm{C}, 15 \mathrm{~min}$ ii) reagents

Cond. B: []$^{+}\left[(\mathrm{S})-\mathrm{TRIP}^{-}(5 \mathrm{~mol} \%)\right.$ and reagents

Scheme 2. Evaluation of []$^{+}[(S)-T R I P]^{-}$in enantioselective $[2+2+2]$ cycloaddition.

The influence of the amount of $\mathrm{Ag}(S)$-TRIP on the rhodium complexes was then assessed by ${ }^{31} \mathrm{P}$ NMR. When 1 equiv of $\mathrm{Ag}(S)$-TRIP vs $\mathrm{Rh}$ is used ([Rh(COD)Cl $]_{2} 0.5$ equiv, dppb 1 equiv, $\mathrm{Ag}(S)$-TRIP 1 equiv), the major product is $\left[\mathrm{I}^{+}[(S) \text {-TRIP] }]^{-}\right.$as discussed above (Figure 5, spectrum 1). When adding more $\mathrm{Ag}(S)$-TRIP, the latter does not accumulate in the reaction mixture but generates two new species II and III. Their proportions grow with increasing amounts of $\mathrm{Ag}(S)$-TRIP (spectra 2-6). Disappearance of $\left[I^{+}[(S)-T R I P]^{-}\right.$is virtually achieved with 2.2 equiv of $\mathrm{Ag}(S)$-TRIP (spectrum 4).

Species II shows four different sets of signals, at $\delta 21.6\left(\mathrm{~d},{ }^{1} \mathrm{~J}\right.$ $\left.\left({ }^{103} \mathrm{Rh}-{ }^{31} \mathrm{P}\right)=152 \mathrm{~Hz}\right), 12.8\left(\mathrm{~d},{ }^{1} \mathrm{~J}\left({ }^{109} \mathrm{Ag}-{ }^{31} \mathrm{P}\right)=820 \mathrm{~Hz}\right.$ and d, ${ }^{1} \mathrm{~J}$ $\left.\left({ }^{107} \mathrm{Ag}-{ }^{31} \mathrm{P}\right)=710 \mathrm{~Hz}\right), 7.1(\mathrm{br} \mathrm{s}, \mathrm{P}(\mathrm{O}) \mathrm{OAg})$ and $3.5(\mathrm{~s}, \mathrm{P}(\mathrm{O}))$ ppm. It is a highly dissymmetric complex, bearing one exceptionally shielded COD double bond ( ${ }^{1} \mathrm{H}$ NMR: $\delta 2.80(1 \mathrm{H})$, 2.63 ppm (1 H); ${ }^{13} \mathrm{C}$ NMR: $\delta 70.5,68.0$ ppm). Its ${ }^{103} \mathrm{Rh}$ NMR signal splits as a doublet (and not a triplet as in species []$^{+}[(S)$ TRIP] $^{-}$) and shifts $993 \mathrm{ppm}$ downfield, from $\delta-8644 \mathrm{ppm}$ (species []$^{+}[(S)-\mathrm{TRIP}]^{-}$) to $\delta-7651 \mathrm{ppm} \cdot{ }^{[2020 \mathrm{~b}]}$ Both are speaking for the replacement of one of the phosphine by an oxygen ligand. ${ }^{[21]}$ The latter downfield shift would probably arise from decoordination of one end of the dppb ligand by excess $\operatorname{Ag}(S)$ TRIP and concomitant coordination of the phosphate. Indeed, ${ }^{31} \mathrm{P}_{-}{ }^{109} \mathrm{Ag} \mathrm{HMQC}$ revealed a doublet at $\delta 426 \mathrm{ppm}\left({ }^{1} \mathrm{~J}\left({ }^{31} \mathrm{P}-\right.\right.$ $\left.{ }^{109} \mathrm{Ag}=820 \mathrm{~Hz}\right)$ ), consistent with a two coordinated linear silver complex. ${ }^{[27]}$ The postulated $\mathrm{Rh}(\mathrm{COD})(\mathrm{dppb})((S)-\mathrm{TRIP})(\mathrm{Ag}(S)$ TRIP) structure II (Figure 2) matches 1D and 2D experiments (SI, sections 3.1 to 3.3 ). ${ }^{31} \mathrm{P}-{ }^{103} \mathrm{Rh} 1 \mathrm{D}$ HMQC experiment confirmed that, this time, the phosphate is an X-type ligand (SI, spectra SI15). ${ }^{[28]}$ Moreover, the bulky cationic structure $[\mathrm{II}-(S)-\mathrm{TRIP}]^{+}$was detected by $\mathrm{ESI}(+)$ analysis (SI, section 3.5). It is worthy to note that only traces of the latter were detected, which is consistent with the low ionic character of the Rh-TRIP bound in this complex. This cation is pretty stable, as increasing energy does not lead to subsequent fragmentation. Particularly, cation [I] at $\mathrm{m} / \mathrm{z} 637$ was not detected by MS/MS analysis. 


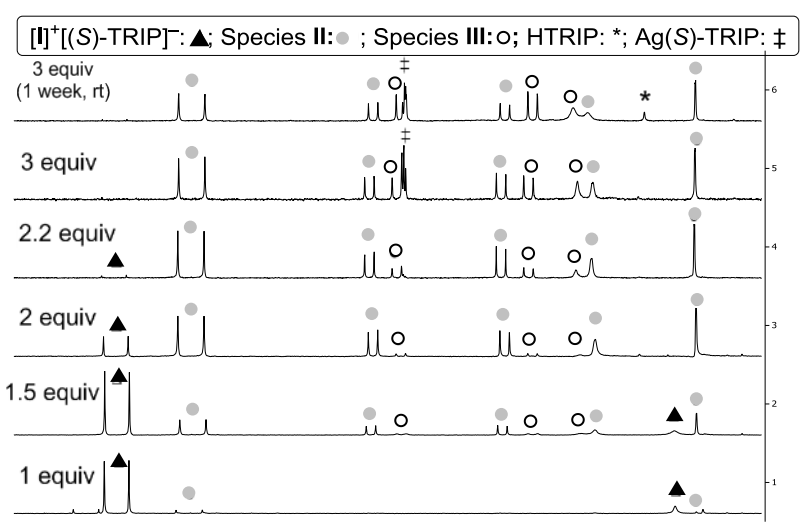

${ }^{31} \mathrm{P}$ NMR spectra were recorded at $162 \mathrm{MHz}, 300 \mathrm{~K}$

Figure 5. ${ }^{31} \mathrm{P}$ NMR monitoring of the metallic species as a function of $\mathrm{Ag}(S)$ TRIP equivalents. ${ }^{[18]}$

The NMR data of species III reveal a symmetric structure with two phosphorous patterns at $\delta 11.8\left(\mathrm{~d}, J\left({ }^{109} \mathrm{Ag}-{ }^{31} \mathrm{P}\right)=820 \mathrm{~Hz}\right.$ and $\mathrm{d}, J\left({ }^{107} \mathrm{Ag}-{ }^{31} \mathrm{P}\right)=710 \mathrm{~Hz}$ ), and 7.7 (br s, P(O)OAg) ppm. The postulated bis-silver structure $\left[(\mathrm{dppb})(\mathrm{Ag}(S)-\mathrm{TRIP})_{2}\right]$ for this complex was corroborated by $1 \mathrm{D}$ and $2 \mathrm{D}$ experiments, as well as $\mathrm{ESI}(+)$ which revealed ion peaks for $\left[\mathrm{III}_{+} \mathrm{Ag}\right]^{+}$at $\mathrm{m} / \mathrm{z} 2253.9$ and [III-TRIP] ${ }^{+}$at $m / z 1393.5$ (SI, section 4). The same NMR features were recorded for a mixture of dppb with 2 equiv of $\mathrm{Ag}(S)$-TRIP in $\mathrm{CD}_{2} \mathrm{Cl}_{2}$ at rt. Of note, this independentlysynthesized complex is catalytically inactive.

We then monitored the evolution of the species in conditions close to those of the reaction, in the presence of the diyne and isocyanate reagents $\left(\left(\mathrm{CD}_{2} \mathrm{Cl}\right)_{2}, 70{ }^{\circ} \mathrm{C}\right)$ with 2 equiv $\mathrm{Ag}(\mathrm{S})$-TRIP (10 mol\%) vs Rh, starting from []$^{+}[(S)-T R I P]^{-} / I I / I I I=1 / 3.5 / 1$ (Figure 6). A 2/1.4/1 ratio was reached after $4.5 \mathrm{~h}$. It is worth underlying that during this study, no reaction intermediate or other catalytic species could be observed by ${ }^{31} \mathrm{P}$ or ${ }^{1} \mathrm{H}$ NMR.

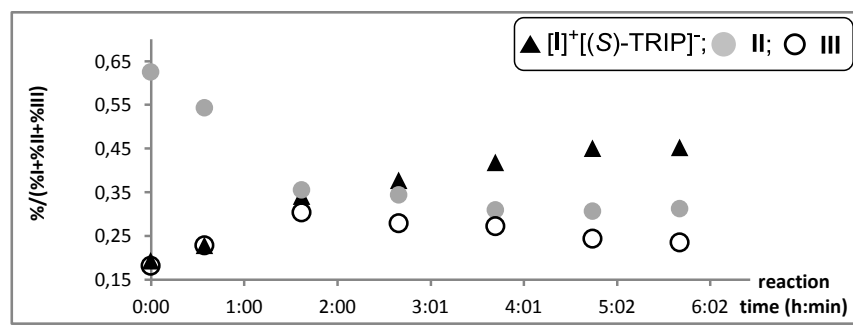

Figure 6. Evolution of the species in the reaction mixture $\left({ }^{31} \mathrm{P} N M R,\left(\mathrm{CD}_{2} \mathrm{Cl}\right)_{2}\right.$, $201 \mathrm{MHz}, 343 \mathrm{~K}, c 0.005 \mathrm{M})$

${ }^{1} \mathrm{H}$ EXSY (EXchange SpectroscopY) study showed that species []$^{+}[(S)-T R I P]^{-}$and II are indeed in equilibrium in the reaction mixture, i.e. coordination/decoordination of silver phosphate occurs with exchange rate constants $k_{1}=$ $0.012 \pm 0.001 \mathrm{~s}^{-1}$ and $k_{-1}=0.049 \pm 0.01 \mathrm{~s}^{-1}$ at $300 \mathrm{~K}$ (Scheme 3). A conformational equilibrium was also revealed by the observation of the NMR signals of the COD protons which exchange by pairs. Since the dppb protons do not exchange, this equilibrium can be explained by the flip of the Rh-dppb- $\mathrm{Ag}(S)$-TRIP side chain above and below the rhodium atom. This second equilibrium occurs with an exchange rate constant of $k^{\prime}=0.034$ $\pm 0.005 \mathrm{~s}^{-1}\left(\mathrm{SI}\right.$, section 5). ${ }^{[29]}$

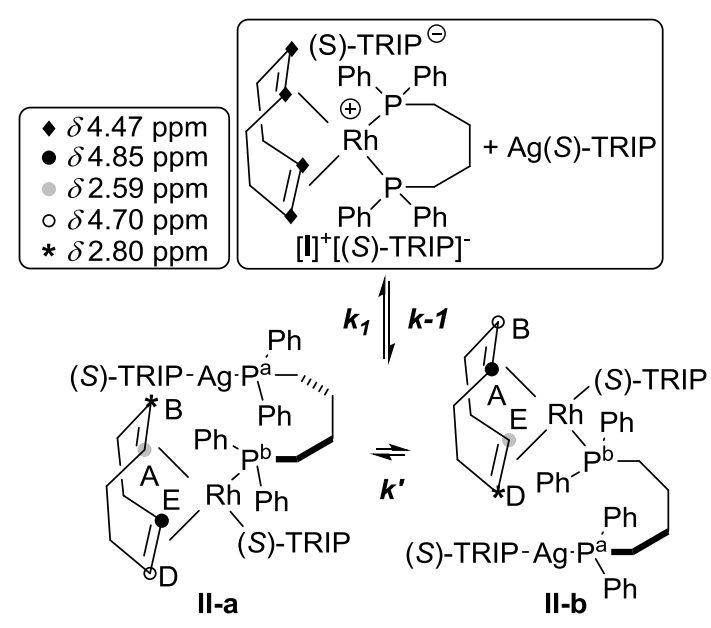

Scheme 3. ${ }^{1} \mathrm{H}$ EXSY study of the equilibrium between species $\left[I^{+}[(S)-T R I P]\right.$ $\mathrm{Ag}(\mathrm{S})$-TRIP and II $(300 \mathrm{~K})$.

The free energy of the $\mathrm{Rh} / \mathrm{Ag}$ transmetallation of one phosphine moiety was estimated by DFT computations using $\left[(\mathrm{MeO})_{2} \mathrm{PO}_{2}\right]^{-}$as model phosphate (Scheme 4). The calculations were carried out at the M06/SDD $(R h, A g) 6-31+G(d, p) / / B 3 L Y P /$ LANL2DZ(Rh,Ag)6-31Gd) level using the Gaussian 09 software package (SI, section 6$)$.

As shown by the quite long $\mathrm{CH}-\mathrm{O}$ distances of 2.06 and $2.08 \AA$ respectively in $[\mathrm{I}]\left[(\mathrm{MeO})_{2} \mathrm{PO}_{2}\right]$-calc, the binding of the phosphate to $\left[\mathrm{I}^{+}\right.$is achieved through weak hydrogen bonds in the gas phase. One phenyl moiety and one $\mathrm{CH}_{2}$ of dppb serve as hydrogen bond donors. Of note, another isomer in which the COD ligand plays the role of hydrogen bond donor was also computed but it was found less stable than [I][(MeO $\left.)_{2} \mathrm{PO}_{2}\right]$-calc by $3 \mathrm{kcal} / \mathrm{mol}$. The computed $\Delta G_{298}$ for $[\mathrm{I}]\left[(\mathrm{MeO})_{2} \mathrm{PO}_{2}\right]$-calc + $\left.\mathrm{Ag}(\mathrm{MeO})_{2} \mathrm{PO}_{2}\right) \rightarrow$ II-calc is of $-40.4 \mathrm{kcal} / \mathrm{mol}$. This large exergonicity supports the proposed phosphine exchange.

We then evaluated these rhodium species in the $[2+2+2]$ cycloaddition reaction of diyne $\mathbf{1 a}$ with isocyanate $\mathbf{2 a}$ under the conditions defined in Figure 7. As shown above, with $5 \mathrm{~mol} \%$ of $\mathrm{Ag}(S)$-TRIP, the catalytic mixture is mostly composed of []$^{+}[(S)-T R I P]^{-}$. With $10 \mathrm{~mol} \%$ of $\mathrm{Ag}(S)$-TRIP, it is enriched in species II. Both catalytic systems led to full conversion in about $1 \mathrm{~h}$ at $70^{\circ} \mathrm{C}$. However, the initial rate is higher with $5 \mathrm{~mol} \%$ $\mathrm{Ag}(S)$-TRIP. 

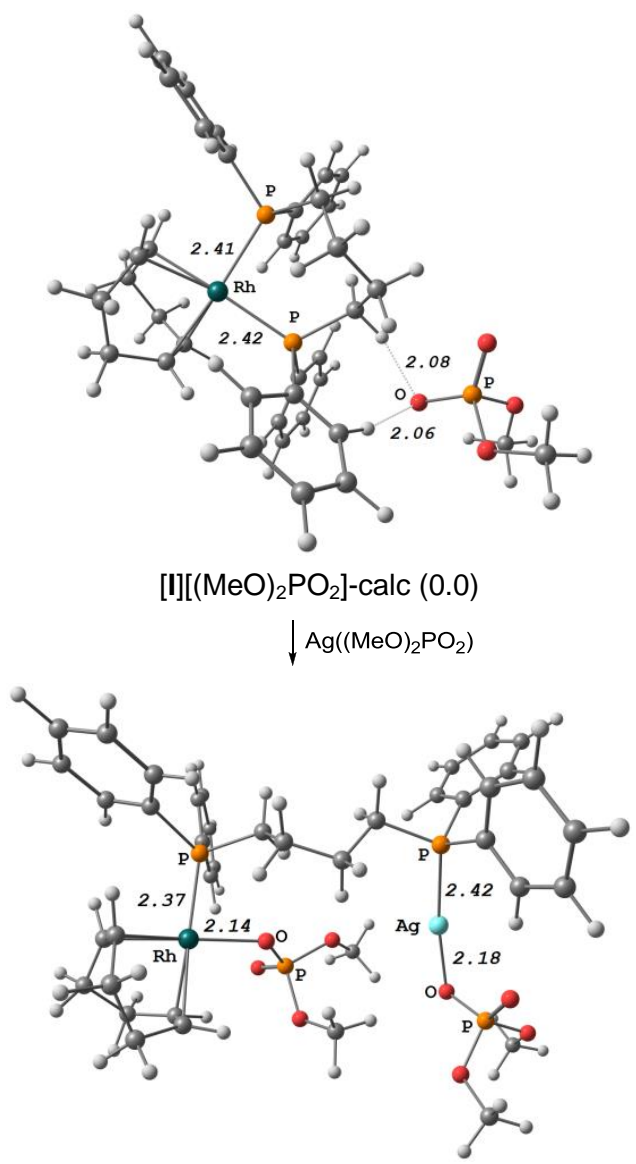

II-calc $(-40.4)$

Scheme 4. Computed $\mathrm{Rh} / \mathrm{Ag}$ transmetallation ( $\mathrm{kcal} / \mathrm{mol}$, distances in $\AA$ )
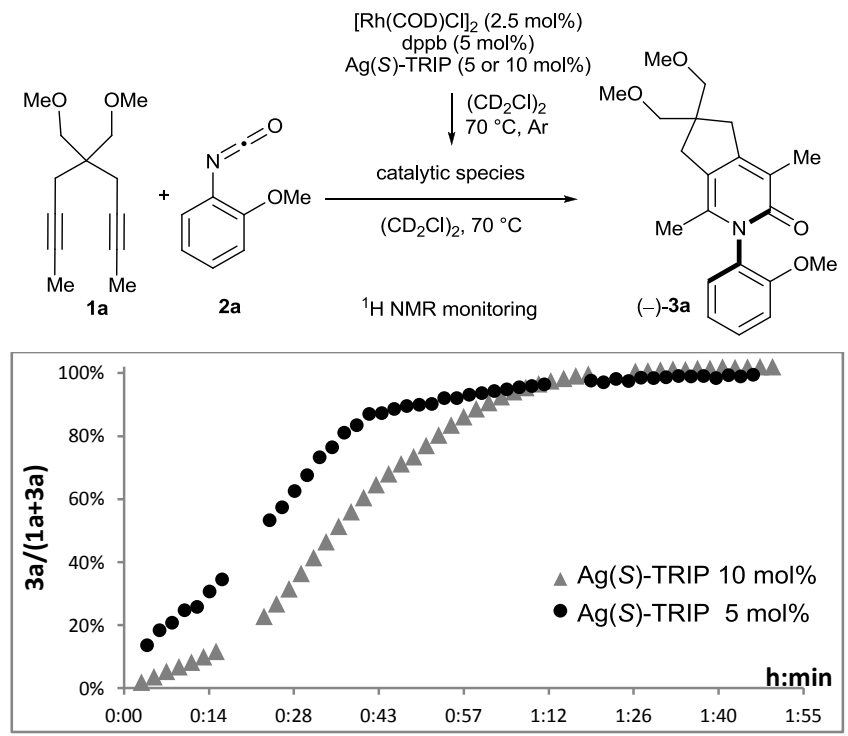

Figure 7. ${ }^{1} \mathrm{H}$ NMR monitoring of the reaction $\left(600 \mathrm{MHz},\left(\mathrm{CD}_{2} \mathrm{Cl}\right)_{2}, 343 \mathrm{~K}\right)$
We then analyzed the enantiomeric excess of the resulting pyridone $3 \mathbf{a}$ as a function of the $\mathrm{Ag}(S)-\mathrm{TRIP} /[\mathrm{Rh}]$ ratio (Table 1 ). With 0.5/1 ratio, a low 55/45 er was measured (entry 1). Significant increase of the er to $77 / 23$ was observed with a $0.9 / 1$ ratio (entry 2). An excess of silver compared to rhodium further raised the er (entries 3-5). When a larger excess of $\mathrm{Ag}(S)$-TRIP is introduced (3/1 ratio), species III accumulates but the er remains similar (83/17, entry 6$)$. These results suggest that species II plays a positive effect on the stereoselectivity. To probe this hypothesis, we compared the use of the isolated complex []$^{+}[(S)-T R I P]^{-}(5 \mathrm{~mol} \%)$ without or with addition of $\mathrm{Ag}(S)$-TRIP (2.5 mol\%) which should generate the [I] $]^{+}[(S)$-TRIP] /II mixture in solution. Whereas as noted in Scheme 2 the isolated complex []$^{+}[(S)-T R I P]^{-}$alone led to a $75 / 25$ er (entry 7 ), pyridone 3a was obtained in an improved 88/12 er when additional $\mathrm{Ag}(\mathrm{S})$-TRIP was used (entry 8 ). This finding comforts the beneficial role of species II in the enantioselectivity of the cycloaddition. However, as $\left[\mathrm{I}^{+}[(S)-\mathrm{TRIP}]^{-}\right.$and II are in equilibrium, we cannot exclude that II is catalytically inactive and that $\mathbf{I}$ is the only active species. The boost of the enantioselectivity in the presence of II may therefore result from the excess $\operatorname{Ag}(S)$-TRIP in the reaction mixture.

Table 1. Influence of $\mathrm{Ag}(S)-\mathrm{TRIP} /[\mathrm{Rh}]$ ratio on the er

$$
\mathbf{1 a}+\mathbf{2 a} \frac{\mathbf{A}, \mathbf{B} \text { or } \mathbf{C}}{\left(\mathrm{CH}_{2} \mathrm{Cl}\right)_{2}, 80{ }^{\circ} \mathrm{C}}(-)-3 \mathbf{a}
$$

Conditions A: i) $\left[\mathrm{Rh}(\mathrm{COD}) \mathrm{Cl}_{2}\right.$ (2.5 mol\%), dppb (5 mol\%), Ag(S)-TRIP (x mol\%), $\left(\mathrm{CH}_{2} \mathrm{Cl}\right)_{2}, 80^{\circ} \mathrm{C}, 15 \mathrm{~min}$ ii) reagents

Conditions B: []$^{+}\left[(S)-T_{R I P}\right]^{-}(5 \mathrm{~mol} \%)$ and reagents

Conditions C: $i)[]^{+}[(S)-T R I P]^{-}(5 \mathrm{~mol} \%), A g(S)-T R I P(x$ mol\%) $\left(\mathrm{CH}_{2} \mathrm{Cl}\right)_{2}, 80^{\circ} \mathrm{C}, 15 \mathrm{~min}$ ii) reagents

\begin{tabular}{cccccc}
\hline Entry & Cond. & $\mathrm{x}(\mathrm{mol} \%)$ & $\mathrm{Ag}(\mathrm{S})-\mathrm{TRIP} /[\mathrm{Rh}]$ & $\begin{array}{c}\text { yield( } \\
\%)\end{array}$ & $e r^{2}$ \\
\hline 1 & $\mathrm{~A}$ & 2.5 & $0.5 / 1$ & 87 & $55 / 45$ \\
2 & $\mathrm{~A}$ & 4.5 & $0.9 / 1$ & 91 & $77 / 23$ \\
3 & $\mathrm{~A}$ & 6.5 & $1.3 / 1$ & 91 & $84 / 16$ \\
4 & $\mathrm{~A}$ & 7.5 & $1.5 / 1$ & 93 & $84 / 16$ \\
5 & $\mathrm{~A}$ & 10 & $2 / 1$ & 93 & $85 / 15$ \\
6 & $\mathrm{~A}$ & 15 & $3 / 1$ & 76 & $83 / 17$ \\
7 & $\mathrm{~B}$ & 0 & $1 / 1$ & 79 & $75 / 25$ \\
8 & $\mathrm{C}$ & 2.5 & $1.5 / 1$ & 70 & $88 / 12$ \\
\hline
\end{tabular}

[a] HPLC, see SI, section 3.4 .

\section{Conclusion}

For the first time, some physical evidence of the counterionic character of the TRIP anion in an organometallic species has been established. Using NMR, MS and DFT calculations, we have studied the organometallic species involved in phosphatedirected Rh-catalyzed [2+2+2] cycloaddition of diynes to isocyanates. The cationizing agent $\operatorname{Ag}(S)$-TRIP, used in slight excess compared to the rhodium complex, gives rise to various 
species in equilibrium. The major one, []$^{+}[(S)-T R I P]^{-}$, leads to the desired pyridone in 75/25 er even in the absence of excess of silver salt. It is a loose ion pair and the counterionic character of the phosphate in this complex has been ascertained by DOSY and other NMR experiments. With an excess of silver salt, a second species appears, in equilibrium with the first one. It is the bimetallic $\operatorname{Rh}(\mathrm{COD})(\mathrm{dppb})((S)-\mathrm{TRIP})(\mathrm{Ag}(S)-\mathrm{TRIP})$ species II which presence boosts the reaction enantioselectivity. In this species, the ${ }^{31} \mathrm{P}-{ }^{103} \mathrm{Rh} 1 \mathrm{D}$ HMQC experiment showed that the phosphate is coordinated to the metal. Clearly the question as to wether a phosphate is a ligand or a counterion in the organometallic species involved in ACDC cannot be answered simply. Actually it depends, and our work suggests that the two options may coexist.

\section{Experimental Section}

Electronic Supplementary Information (SI) available: full NMR and ESI characterizations for complexes $\left[\mathrm{II}^{+}[(S)-\mathrm{TRIP}]^{-}\right.$, II and III; experimental procedures; HPLC traces; kinetic studies; coordinates and energy of the calculated species.

\section{Acknowledgements}

This work was supported by the CNRS, UPMC, IUF and Agence Nationale de la Recherche (ANR-09-BLAN-108 SACCAOR). We warmly thank A. Bernard, G. Gontard and Dr F. Ribot for NMR studies, E. Kolodziej for HPLC analysis, Dr H. Amouri, Dr J. Moussa and Dr M. Ménand for useful discussion. We used the computing facility of the CRIHAN (project 2006-013).

Keywords: homogeneous catalysis $\cdot$ ACDC $\bullet$ chirality $\cdot$ rhodium - $[2+2+2]$ cycloaddition

[1] B. Kasprzyk-Hordern, Chem. Soc. Rev., 2010, 39, 4466.

[2] For two recent reviews on enantioselective metal-catalyzed transformations, see: a) A. H. Cherney, N. T. Kadunce S. E. Reisman, Chem. Rev., 2015, 115, 9587; b) P. Loxq, E. Manoury, R. Poli, E. Deydier A. Labande, Coord. Chem. Rev., 2015, DOI: 10.1016/j.ccr.2015.07.006

[3] For recent reviews, see: a) Y-M. Wang, A. D. Lackner F. D. Toste Acc. Chem. Res., 2014, 47, 889; b) B. M. Trost M. Rao, Angew. Chem. Int Ed., 2015, 54, 5026. For recent reports, see inter alia: c) S. Handa L. M. Slaughter, Angew. Chem. Int. Ed., 2012, 51, 2912; d) M. Barbazanges L. Fensterbank, ChemCatChem, 2012, 4, 1065; e) K Ohmatsu, M. Ito, T. Kunieda T. Ooi, Nat. Chem., 2013, 4, 473.

[4] O. I. Kolodiazhnyi, Tetrahedron, 2003, 59, 5953.

[5] For reviews, see: a) J. Lacour D. Moraleda, Chem. Commun., 2009, 7073; b) C. Zhong X Shi, Eur J. Org. Chem. 2010, 2999; c) R. J. Phipps, G. L. Hamilton F. D. Toste, Nature Chem., 2012, 4, 603; d) M Mahlau B. List, Isr. J. Chem., 2012, 52, 630; e) M. Mahlau B. List, Angew. Chem. Int. Ed., 2013, 52, 518; f) E. P. Ávila G. W. Amarante, ChemCatChem, 2012, 4, 1713; g) A. Parra, S. Reboredo, A. M. Martín Castro J. Alemán, Org. Biomol. Chem., 2012, 10, 5001; h) K. Brak E. N. Jacobsen, Angew. Chem. Int. Ed., 2013, 52, 534; i) M. Raynal, P. Ballester, A. Vidal-Ferran P. W. N. M. van Leeuwen, Chem. Soc. Rev., 2014, 43, 1660; j) D. Parmar, E. Sugiono, S. Raja M. Rueping, Chem. Rev., 2014, 114, 9047; k) M. Jia M. Bandini, ACS Catal., 2015, 5, 1638.

[6] a) D. B. Llewellyn, D. Adamson B. A. Arndtsen, Org. Lett., 2000, 2, 4165 ; b) D. B. Llewellyn B. A. Arndtsen, Tetrahedron Asym., 2005, 16,1789 .
[7] a) V. Komanduri M. J. Krische, J. Am. Chem. Soc., 2006, 128 16448; b) J. R. Zbieg, E. Yamaguchi, E. L. McInturff M. J. Krische, Science, 2012, 336, 324

[8] a) S. Mukherjee B. List, J. Am. Chem. Soc., 2007, 129, 11336; b) G. L. Hamilton, E. J. Kang, M. Mba F. D. Toste, Science, 2007, 317 496; c) R. L. LaLonde, Z. J. Wang, M. Mba, A. D. Lackner, F. D. Toste, Angew. Chem., Int. Ed., 2010, 49, 598.

[9] a) D. Uraguchi M. Terada, J. Am. Chem. Soc., 2004, 126, 5356; b) T. Akiyama, J. Itoh, K. Yokota K. Fuchibe, Angew. Chem. Int. Ed., 2004, 43, 1566

[10] For the contribution of our laboratory in the field of anion-directed transition metal catalysis, see: a) M. Augé, A. Feraldi-Xypolia, M. Barbazanges, C. Aubert, L. Fensterbank, V. Gandon C. Ollivier Org. Lett., 2015, 17, 3754; b) M. Augé, M. Barbazanges, A. T. Tran, A. Simonneau, P. Elley, H. Amouri, C. Aubert, L. Fensterbank, V. Gandon, M. Malacria, J. Moussa C. Ollivier, Chem. Commun., 2013 49, 7833; c) M. Barbazanges, M. Augé, J. Moussa, H. Amouri, C. Aubert, C. Desmarets, L. Fensterbank, V. Gandon, M. Malacria C Ollivier, Chem. Eur. J., 2011, 17, 13789

[11] D. Zuccaccia, L. Belpassi, F. Tarantelli A. Macchioni, J. Am. Chem. Soc., 2009, 131, 3170 .

[12] C. Reichardt, Solvents solvent Effect in Organic Chemsitry, $3^{\text {rd }}$ ed., Wiley-VCH, Weinheim, 2003.

[13] a) K. Aikawa, M. Kojima K. Mikami, Angew. Chem. Int. Ed., 2009 48, 6073; b) M. Raducan, M. Moreno, C. Bour A. M. Echavarren, Chem. Commun., 2012, 48, 52; c) G. Jiang, R. Halder, Y. Fang B. List, Angew. Chem. Int. Ed., 2011, 50, 9752.

[14] B. N. Nguyen, L. A. Adrio, E. M. Barreiro, J. B. Brazier, P. Haycock, K. K. (Mimi) Hii, M. Nachtegaal, M. A. Newton J. Szlachetko, Organometallics, 2012, 31, 2395.

[15] a) G. Jiang B. List, Chem. Commun., 2011, 47, 10022; b) K. Ohmatsu, M. Ito, T. Kunieda T. Ooi, J. Am. Chem. Soc., 2013, 135 590; c) K. Ohmatsu, Y. Hara T. Ooi Chem. Sci., 2014, 5, 3645.

[16] G. Jindal R. B. Sunoj, J. Org. Chem., 2014, 79, 7600.

[17] For a related study, see: V. M. Williams, J. R. Kong, B. J. Ko, Y Mantri, J. S. Brodbelt, M.-H. Baik, M. J. Krische, J. Am. Chem. Soc 2009, 131, 16054 .

[18] NMR studies were performed in a sealed NMR tube, loaded in a glove box. As long as no heating is required, the ion pair was preformed studied in $\mathrm{CD}_{2} \mathrm{Cl}_{2}$, at $300 \mathrm{~K}$, at $c 0.02 \mathrm{M}$, see Supporting Information (SI), section 1.

[19] ${ }^{103} \mathrm{Rh}$ NMR were performed in $\mathrm{CD}_{2} \mathrm{Cl}_{2}, 19 \mathrm{MHz}, 300 \mathrm{~K}, \Xi 3.186 \mathrm{MHz}$ see L. Carlton, in Rhodium-103 NMR in Annual Reports on NMR spectroscopy, ed. G. A. Webb, Elsevier Academic Press Inc., 2008, vol. 63, chap. 3, pp. 49-178.

[20] a) $\delta$-8466 relative to $\Xi 3.186 \mathrm{MHz}$ ie $\delta-168 \mathrm{ppm}$ relative to $\Xi 3.16$ $\mathrm{MHz}$; b) $\delta-7651 \mathrm{ppm}$ relative to $\Xi 3.186 \mathrm{MHz}$ ie $\delta 654 \mathrm{ppm}$ relative to $\Xi$ 3.16 $\mathrm{MHz}$.

[21] a) J. M. Ernsting S. Gaemers, C. J. Elsevier, Magn. Reson. Chem., 2004, 42, 721; b) A. Fabrello, C. Dinoi L.Perrin, P. Kalck, L. Maron, M. Urrutigoity O. Dechy-Cabaret, Magn. Reson. Chem., 2010, 48, 848.

[22] For selected reviews on DOSY, see: a) P. S. Pregosin, Pure Appl. Chem., 2009, 81, 615; b) A. Macchioni, G. Ciancaleoni, C Zuccaccia D. Zuccaccia, Chem. Soc. Rev., 2008, 37, 479; c) G. Bellachioma, G. Ciancaleoni, C. Zuccaccia, D. Zuccaccia A Macchioni, Coord. Chem. Rev., 2008, 252, 2224; d) P. S. Pregosin, Prog. Nucl. Magn. Reson. Spectrosc., 2006, 49, 261; e) A Macchioni, Chem. Rev., 2005, 105, 2039; g) P. S. Pregosin, P. G. A. Kumar I. Fernandez, Chem. Rev., 2005, 105, 2977.

[23] J. A. Raskatov, A. L. Thompson, A. R. Cowley, T. D.W. Claridge J. M. Brown, Chem. Sci., 2013, 4, 3140 .

[24] Dynamics Center software was used to calculate the $D$ values.

[25] $\quad r_{H}$ (hydrodynamic radius of the species) was obtained from the Stokes Einstein relation $D=\frac{k T}{6 \pi r_{H}}$, with a viscosity $\eta=0.410 \mathrm{E}-3 \mathrm{~kg} / \mathrm{m} / \mathrm{s}$ for $\mathrm{CH}_{2} \mathrm{Cl}_{2}$ at $300 \mathrm{~K}$, see Chemical Properties Handbook; McGraw-Hill: New York, 1999.

[26] $\mathrm{Ag}(S)$-TRIP DOSY led to the following diffusion coefficient: $D_{[\mathrm{Ag}(S) \text {-TRIP] }}=$ $7.1 \mathrm{E}-10 \mathrm{~m}^{2} / \mathrm{s}$ (i.e. a hydrodynamic radii of $r_{H}=7.5 \AA$ ) (SI, section 2.7 )

[27] a) A. Cingolani, F. Marchetti, C. Pettinari, R. Pettinari, B. W. Skelton, A. H. White, Inorg. Chem., 2002, 41, 115; b).S. M. Socol, R. A. Verdake Inorg. Chem. 1984, 23, 3487; c) S. M. Socol, R. A. Jacobson,J. G. Verkade, Inorg. Chem. 1984, 23, 88.

[28] Due to complex ${ }^{1} \mathrm{H}$ NMR, DOSY of I/II/III mixture was not workable, see SI, section 3.6.

[29] EXSYCalc software package (Mestrelab Research) was used to extract exchange constants from EXSY experiments. 

Let's open the black box: Using NMR, MS and DFT calculations, we have studied the organometallic species involved in phosphatedirected Rh-catalyzed [2+2+2] cycloaddition of diynes to isocyanates. For the first time, some physical evidence of the counterionic character of the TRIP anion in an organometallic species has been established.

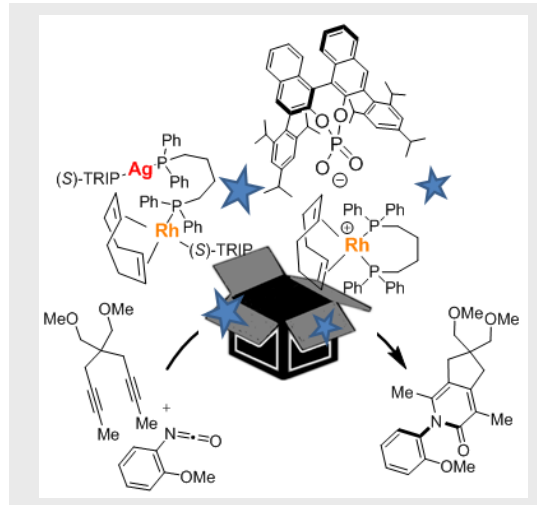

Marion Barbazanges, * Elsa Caytan, Denis Lesage, Corinne Aubert, ${ }^{*}$ Louis Fensterbank, * Vincent Gandon, Cyril Ollivier

Page No. - Page No.

Chiral Phosphate in RhodiumCatalyzed Asymmetric [2+2+2] Cycloaddition: Ligand, Counterion or Both? 